\title{
Covid 19 Impact on “Maternal Health Care Quality” in Rural India
}

\author{
Vidyadhar Bangal \\ Pravara Institute of Medical Sciences (DU) Loni, India
}

Corresponding Author: Vidyadhar Bangal, Pravara Institute of Medical Sciences (DU) Loni, India.

Received date: May 20, 2021; Accepted date: June 16, 2021; Published date: June 22, 2021

Citation: Bangal V. (2021) Covid 19 Impact on “Maternal Health Care Quality” in Rural India. J. Obstetrics Gynecology and Reproductive Sciences 5(5) DOI:10.31579/2578-8965/078

Copyright: () 2021, Vidyadhar Bangal , This is an open access article distributed under the Creative Commons Attribution License, which permits unrestricted use, distribution, and reproduction in any medium, provided the original work is properly cited.

Covid -19 pandemic has adversely affected the maternal health in multiple ways. Pregnant women are facing multiple problems and delays in seeking routine care during pregnancy, delivery and postpartum. There is lack of availability and accessibility of maternal health care services in public and private sectors. Government health facilities are geared up in surveillance, testing, quarantine, isolation and treatment of either confirmed or suspect Covid cases. The private health care facilities including maternity homes have put their shutters down with the fear of contracting and spreading the Covid. There is big fear factor and apprehension among all cadres of health care workers about the disease, in view of the disasters and the mortality figures in the most affluent countries in the world.

The problems related to maternal health care services are more common in rural areas. These areas have almost got disconnected from the health care facilities, as the public transport system was on hold for last three to four months. Pregnant women are not getting medical consultations, medications and laboratory and ultra-sonography services. This has resulted into gross delay in detection and referral of high risk pregnancies, who are reporting with serious complications like eclampsia and severe anaemia and ante-partum and postpartum haemorrhage. Fetal malpresentations and growth and developmental abnormalities are getting missed or getting diagnosed late. The maternity homes have stopped the protocol of labour companion in order to maintain social distancing norm. The women in labour, especially in public health facilities are not getting respectful maternity care and are facing the abuse.

Large number of obstetric emergencies are reporting to tertiary care hospitals. There is significant delay in reaching to the hospital due to scarcity of public transport facilities, due to strict lock down and sealing of boundaries of various small towns and districts. The cases with obstetric emergencies are not being accepted by majority of hospitals as they are not registered with them.

There is gross scarcity of blood and blood components in the entire country, rural areas being most affected. Voluntary donors are not coming for blood donation. Government has put restrictions on conducting blood donation/collection camps to avoid spread of disease due to social distancing problems. The cases needing emergency and life saving blood transfusions like ruptured ectopic pregnancies with gross intra-peritoneal haemorrhage, ante-partum haemorrhage, especially accidental haemorrhage and postpartum haemorrhage are worst affected, as their survival depend on quick replacement of blood and blood components.

The health care workers are apprehensive and scared while catering services to the pregnant population, as they are not sufficiently equipped with the adequate personal protective equipments (PPE). There is increase in stress and mental health problems among health care workers in critical care areas. There is increase in percentage of absenteeism among health care workers.

The Covid 19 pandemic has very badly affected the economy and has resulted in gross reduction in per capita income. The Community belonging to lower socio economic class, who has lost its means of livelihood, has to bear the major brunt. The family income has shrunk. The poor and the marginalized have no choice than to have domiciliary deliveries. As a result, more number of women are reporting with complications like eclampsia, severe hypertension, severe anaemia and puerperal sepsis, which are major causes of maternal morbidity and mortality.

Two more reproductive health problems have emerged prominently during covid 19 lockdown period. One of them being domestic violence and second being unplanned pregnancies. Men are suffering from withdrawal of substance abuse, as the substances are either unavailable or inaccessible. Pregnant women have to do more household work than their routine, as all family members including children are confined to home throughout the day. Pregnant women are overworked and are showing signs of fatigue. Nutrition of the pregnant women is adversely affected, as family income is significantly reduced, reflecting on food purchasing capacity. Poor nutrition is resulting into nutritional anaemia, susceptibility to infections, postpartum haemorrhage and fetal growth restriction.

During this challenging time, Government has taken steps to modify the health care delivery system, so that minimum essential care is provided and adverse outcomes are averted. The health care workers are sensitized and educated about the health care needs of the pregnant women in this difficult phase. Unfortunately, in spite of government's efforts, the pregnant women are facing lot many difficulties in receiving the basic maternity services. 
Government of India, through its flagship programme "LaQshya", started many initiatives with the collaboration with an organization called "Nationwide Quality of Care Network (NQOCN). The aim was to improve the intra-partum quality of care for mother and for newborn during immediate neonatal period. The programme began with great promise and resulted in success within short span of time. The Covid 19 pandemic has affected the ongoing activities of this initiative and partially disrupted the momentum gained.

It's a wishful thinking that the government's efforts and the peoples participation across the country, will soon overcome the Covid pandemic and health services will revert back to normalcy.
This work is licensed under Creative Commons Attribution 4.0 License

To Submit Your Article Click Here: Submit Manuscript

DOI: $10.31579 / 2578-8965 / 078$
Ready to submit your research? Choose Auctores and benefit from:

* fast, convenient online submission

* rigorous peer review by experienced research in your field

* rapid publication on acceptance

* authors retain copyrights

* unique DOI for all articles

* immediate, unrestricted online access

At Auctores, research is always in progress.

Learn more www.auctoresonline.org/journals/obstetrics-gynecology-andreproductive-sciences- 